\title{
19 NĂM KINH NGHIỆM VỚI VAN SORIN BICARBON
}

Văn Hùng Dũng*

Chuyên ngành phẫu thuật tim ở Việt Nam đã phát triển khá sớm từ những năm

1950 và trong đó bệnh van tim hậu thấp là một trong những trọng điểm. Do đặc thù của bệnh van tim hậu thấp là dày dính và vôi hóa nên nhiều trường hợp không thể tạo hình van mà phải thay van bệnh nhân bằng van nhân tạo. Tại Viện Tim thành phố Hồ Chí Minh, chúng tôi đã bắt đầu sử dụng van Sorin Bicarbon từ tháng 5 năm 1998. Van cơ học Bicarbon, do tập đoàn LivaNova, Ý sản xuất là loại van cơ học có cấu trúc hai nửa dĩa hình bán nguyệt hơi cong và được làm bằng hợp kim graphite-tungsten có phủ pyrolytic carbon. Khung và bản lề có cấu tạo từ hợp kim titanium và được phủ một lớp Carbofilm ${ }^{\circledR}$, lớp phủ này có tác dụng làm tăng tính tương thích sinh học. Với cấu trúc bản lề nằm trong khung, trục của hai nửa dĩa sẽ xoay tròn khi mở, đặc tính này làm giảm thiểu máu đọng ở vùng bản lề (làm giảm nguy cơ huyết khối) cũng như làm giảm hiện tượng xoáy của dòng máu từ đó làm giảm độ chênh áp ngang van. Vòng ngoài van được làm bằng polyethylene terephthalate cũng được phủ Carbonfilm ${ }^{\circledR}$. Khung van có thể xoay trong vòng van nhờ đó có thể dễ dàng định hướng mở dĩa van theo ý thích. Dù được FDA công nhận từ 1990, van Bicarbon đã được dùng rộng rãi tại châu Âu và châu Á khá sớm từ những năm 1986 -1987[3], [4]. Hiện tại có ba loại van Bicarbon được lưu hành: Bicarbon Fitline, Bicarbon Slimline và Bicarbon Overline (hai loại sau chỉ dành cho van ĐMC).

Chúng tôi thực hiện nghiên cứu này nhằm đánh giá kết quả dài hạn của phẫu thuật thay van tim bằng van nhân tạo cơ học Sorin Bicarbon.

\section{I.BẸNH NHÂN VÀ PHƯƠNG PHÁP NGHIÊN CÚU:}

Chúng tôi hồi cứu các bệnh nhân được thay van tim bằng van nhân tạo cơ học.

Sorin Bicarbon tại Viện Tim thành phố Hồ chí Minh trong khoảng thời gian từ tháng 5 năm 1998 đến hết tháng 12 năm 2008. Vị trí thay van bao gồm van hai lá, van động mạch chủ (ĐMC) hoặc cả hai. Dân số bệnh nhân nghiên cứu được trình bày theo lưu đồ trong trang sau.

Các biến số được trình bày dưới dạng trung bình \pm độ lệch chuẩn. Tỷ lệ còn sống thực tế cũng như tỷ lệ dồn không bị mổ lại được tính theo phương pháp Kaplan-Meier. Các biến cố liên quan đến thay van tim như huyết khối van, thuyên tắc, viêm nội tâm mạc, xuất huyết nặng... được báo cáo đưới dạng tần suất đường thẳng (linearized rate) hay số biến cố xảy ra/bệnh nhânnăm. Số liệu báo cáo được thực hiện theo hướng dẫn của Hội Phẫu thuật Lồng Ngực - Tim mạch Mỹ [1].

Đại đa số bệnh nhân được theo dõi bằng tái khám định kỳ tại Viện Tim thành phố Hồ Chí Minh. Bệnh nhân nào không tái khám trên 1 năm được xem như mất theo dõi. Các bệnh nhân được theo dõi ở trung tâm khác được ghi nhận nhưng bị loại khỏi nghiên cứu. Thời gian thu thập số liệu từ tháng $3 / 2012$ đến tháng $11 / 2012$. Số liệu theo dõi được cập nhật đến tháng 2/2018. Số liệu gốc được nhập và xử lý bằng phần mềm IBM SPSS Statistics 20.0.

\footnotetext{
* Viện Tim thành phố Hồ Chí Minh Ngườ chịu trách nhiệm khoa học: TS. Văn Hùng Dũng Ngày nhận bài: 01/05/2018 - Ngày Cho Phép Đăng: 20/05/2018 Phản Biện Khoa học: PGS.TS. Đặng Ngọc Hùng
} GS.TS. Lê Ngoc Thành 


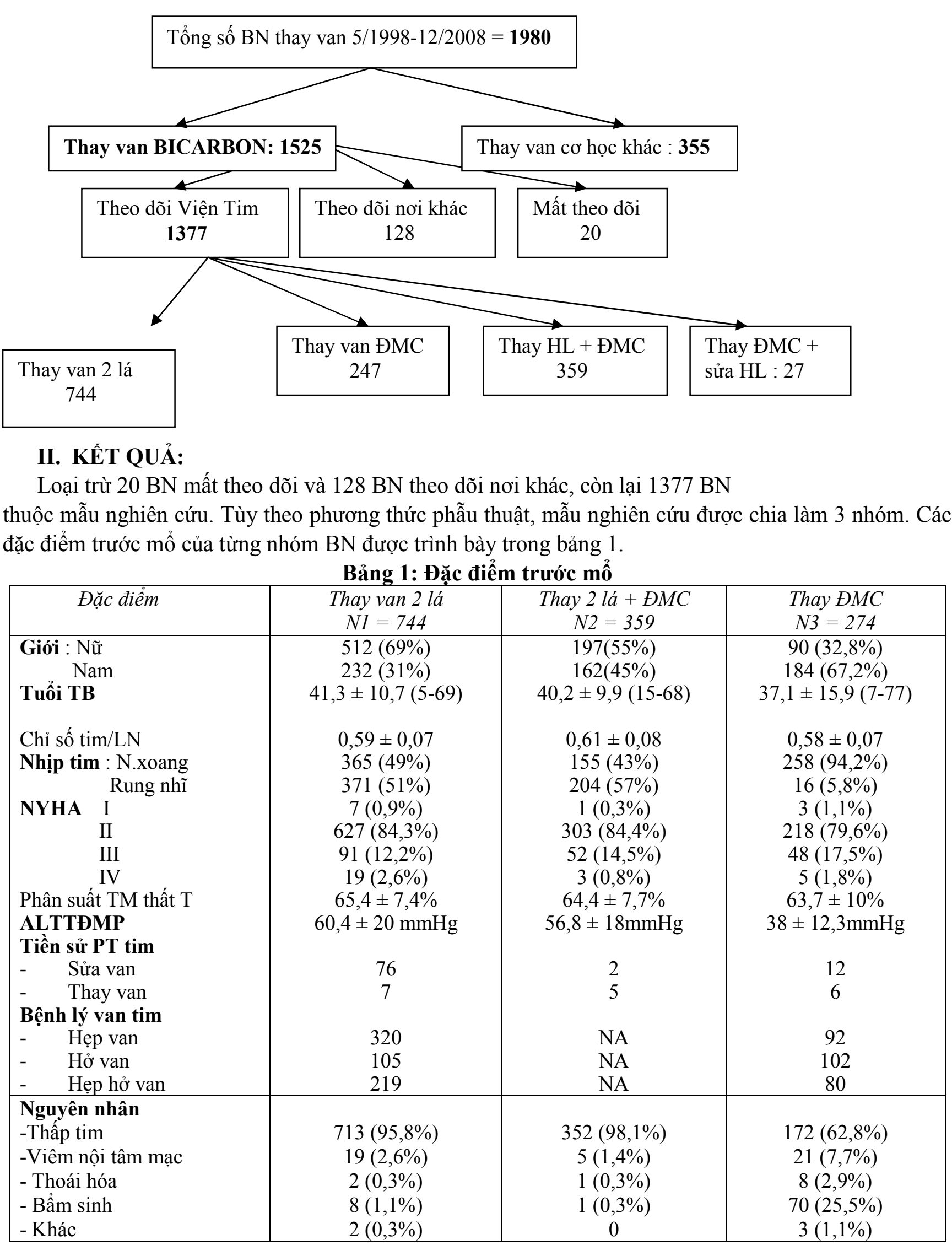


Tử vong phẫu thuật chung là 20 trường hợp (TH) trong đó tử vong của từng nhóm được liệt kê trong bảng 2. Nguyên nhân tử vong lần lượt là : suy tim: 10 , nhiễm trùng: 3 , suy đa cơ quan: 3 , nhồi máu cơ tim : 1 , đột tử : 1 , thuyên tắc não : 1 , vỡ thất trái : 1 .

Các biến chứng sớm trong vòng 30 ngày sau mổ chủ yếu là suy tim, rối loạn nhịp tim, nhiễm trùng phổi, nhiễm trùng xương ức, tràn dịch màng tim, màng phổi, suy thận cấp ( bảng 2).Các biến chứng này làm kéo dài ngày nằm hồi sức cũng như ngày nằm viện và làm tăng chi phí đáng kể. Suy tim nặng ( khi phải hỗ trợ bằng 2 loại thuốc trợ tim trở lên và kéo dài ít nhất 48 giờ) là biến chứng gặp nhiều nhất $(5,4 \%)$ chủ yếu gặp ở nhóm thay van hai lá. Các dạng rối loạn nhịp tim thường thấy sau mổ là rung nhĩ cơn, ngoại tâm thu thất và nhịp chậm .Nhiễm trùng là biến chứng gặp nhiều thứ hai $(4,9 \%)$ chủ yếu là nhiễm trùng phổi do thở máy kéo dài. Viêm xương ức trung thất chiếm 1,5\% (21 TH) với tác nhân thường gặp nhất là Staphylococcus aureus và Pseudomonas aeruginosa.

Các đặc điểm phẫu thuật và hồi sức được trình bày trong bảng 2 như sau :

Bảng 2 : Đặc điểm hồi sức và phẫu thuật

\begin{tabular}{|c|c|c|c|}
\hline Đặc diểm & Thay hai lá & Thay 2 lá $-Ð M C$ & Thay ĐMC \\
\hline Thời gian THNCT & $66,4 \pm 24,5 p$ & $102 \pm 20,5 \mathrm{p}$ & $86,2 \pm 38,6 p$ \\
\hline Thời gian kẹp ĐMC & $47,6 \pm 15,2 p$ & $81,2 \pm 14,3 p$ & $62,9 \pm 24,7 p$ \\
\hline Thời gian nằm ICU & $1,7 \pm 2,1$ & $1,6 \pm 1,6$ & $1,6 \pm 1,7$ \\
\hline & (1-21 ngày ) & (1-22 ngày) & $(1-20)$ \\
\hline Thời gian thở máy & $17 \pm 33,6$ & $14 \pm 13,8$ & $15,7 \pm 25,2$ \\
\hline & (2 - 316 giờ) & (3 -164 giờ) & (1 - 306 giờ) \\
\hline Thời gian nằm viện & $11,6 \pm 2,7$ & $11,9 \pm 2,6$ & $12 \pm 3,6$ \\
\hline & ( 2 - 33 ngày) & ( 6 - 30 ngày) & ( 2 - 38 ngày) \\
\hline \multicolumn{4}{|l|}{ PT đi kèm } \\
\hline ĐóngTLT,TLN,OĐM & 13 & 0 & 37 \\
\hline Lấy huyết khối & 86 & 23 & 0 \\
\hline Tạo hình van hai lá & 0 & 0 & 27 \\
\hline Tạo hình van ba lá & $243(32,6 \%)$ & $86(24 \%)$ & $8(2,9 \%)$ \\
\hline Bắc cầu ĐMV & 9 & 5 & 7 \\
\hline Khác & 23 & 17 & 16 \\
\hline \multicolumn{4}{|l|}{ Biến chứng sớm } \\
\hline - Nhiễm trùng & $36(4,7 \%)$ & $13(3,6 \%)$ & $20(7,3 \%)$ \\
\hline - Suy tim nặng & $46(6,2 \%)$ & $16(4,4 \%)$ & $12(4,4 \%)$ \\
\hline - Rối loạn nhịp & $55(7,4 \%)$ & $12(3,3 \%)$ & $12(4,4 \%)$ \\
\hline - Tràn dịch MNT-MP & $42(5,6 \%)$ & $18(5 \%)$ & $19(6,9 \%)$ \\
\hline - Suy thận cấp & $7(0,9 \%)$ & $2(0,5 \%)$ & $3(1 \%)$ \\
\hline - Suy đa cơ quan & $3(0,4 \%)$ & $1(0,28 \%)$ & 0 \\
\hline - RL định hướng/sảng & $4(0,5 \%)$ & $2(0,5 \%)$ & $5(1,8 \%)$ \\
\hline - XH tiêu hoá nặng & $3(0,4 \%)$ & 0 & $1(0,4 \%)$ \\
\hline
\end{tabular}

THNCT : tuần hoàn ngoài cơ thể ; TLN: thông liên nhĩ; TLT: thông liên thất; OĐM: ống động mạch ; MNT: màng ngoài tim; MP: màng phổi; ICU : đơn vị săn sóc đặc biệt 


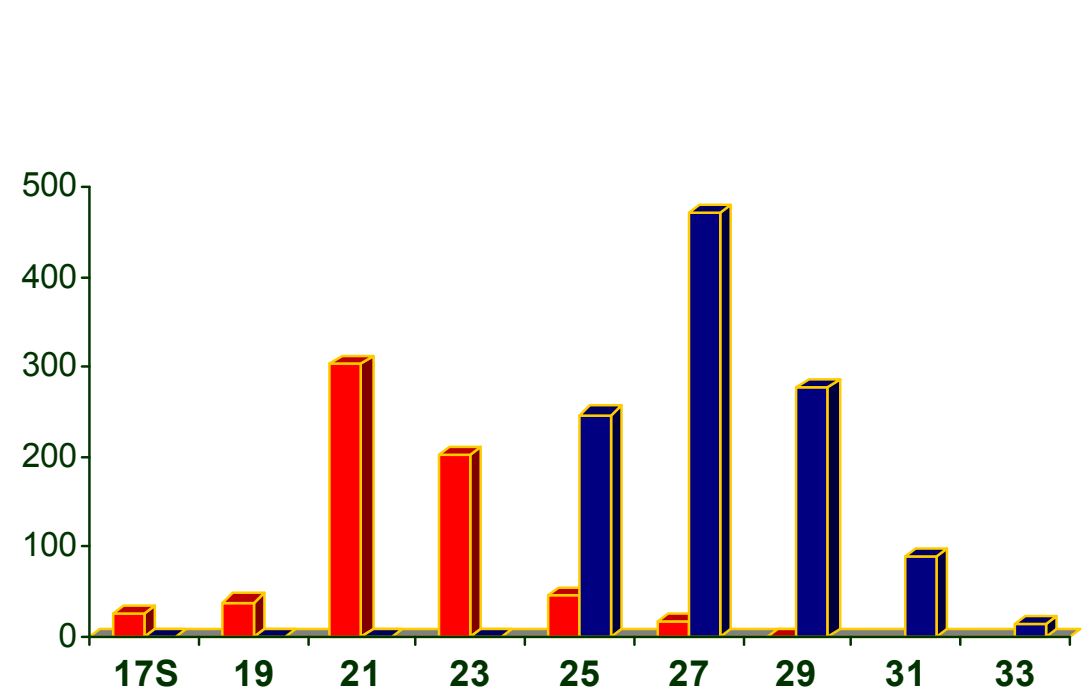

Biểu đồ 1: kích cõ̃ và số lự̛ng van SorinBicarbon đự̂c thay tương ứng

Thời gian theo dõi trung bình là $153,1 \pm 53$ tháng (ngắn nhất 66 tháng và dài nhất là 236 tháng) với tổng thời gian theo dõi là $17653 \mathrm{BN}$ năm. Có 32 BN mất theo dõi $(2,5 \%)$ sau 19 năm theo dõi.

Tử vong muộn có $77 \mathrm{BN}$ (16 xuất huyết não, 15 suy tim mãn, 12 đột tử, 8 ung thư, 7 không rõ nguyên nhân, 4 suy thận, 2 viêm nội tâm mạc và 13 do nguyên nhân khác). Thời gian xảy ra tử vong muộn sớm nhất là 6 tháng và muộn nhất là 186 tháng sau mổ.

Tỷ lệ sống còn thực tế KM sau 19 năm theo dõi là $88,8 \pm 1,8 \%$ ( biểu đồ 2 ).

Đánh giá mức độ suy tim theo NYHA ở thời điểm theo dõi cuối cùng cho thấy đại đa số BN ở NYHA 0 - I : 1190 BN( 93\%).

\section{Các biến chứng liên quan đến van}

-Mổ lại: 59 BN phải mổ lại, nguyên nhân bao gồm huyết khối van : 31 ; rối loạn hoạt động van do mô xâm lấn : 16 ; hở cạnh vòng van : 7 và do nguyên nhân khác : 5 .

Tỷ lệ dồn không bị mổ lại thực tế sau 19 năm là $86,4 \pm 4,7 \%$. 
liên quan thuốc kháng đông mức độ nhẹ. (2) mức độ nặng khi có xuất huyết da niêm nặng phải nhập viện điều trị hoặc xuất huyết não-màng não : $47 \mathrm{TH}(3,5 \%)$ và $12 / 47 \mathrm{TH}$ có xuất huyết nãomàng não đã tử vong.

-Viêm nội tâm mạc nhiễm trùng : $12 \mathrm{BN}$ bao gồm 4 trường hợp xảy ra sớm trong năm đầu tiên, 2 trong số này là VNTMNT tái phát với tác nhân đều là Staphylococcus aureus và đều ở vị trí ĐMC. 8 trường hợp còn lại xảy ra muộn từ 3 đến 10 năm sau mồ. $9 / 12 \mathrm{BN}$ bị VNTM cần phải mổ lại để lấy sùi và thay lại van khác. 2 BN khác chết trước khi được mổ lại.

-Hu van do cấu trúc: chúng tôi không ghi nhận trường hợp nào.

- Hu van không do cấu trúc : 7 TH hở cạnh vòng van trong đó $4 \mathrm{TH}$ hở cạnh vòng van ĐMC và $3 T H$ hở cạnh vòng van hai lá. Tất cả đều phải mổ lại để cố định lại (1 TH) hoặc thay van mới.

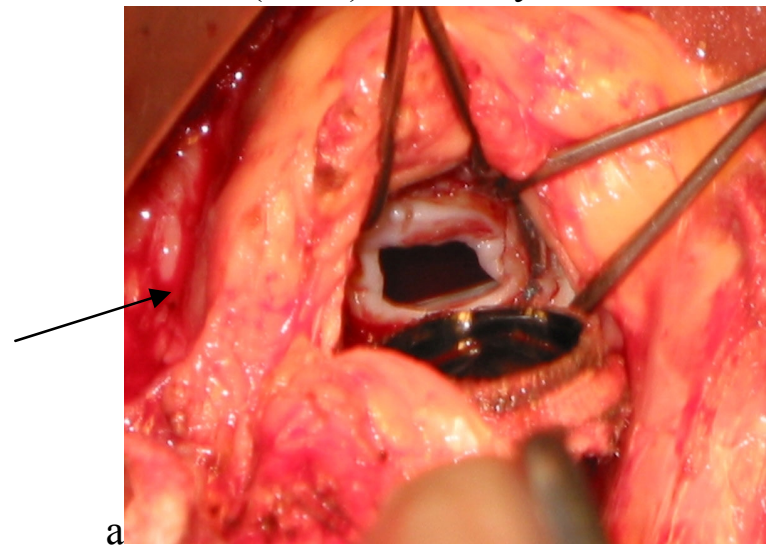

-Pannus: Hiện tượng mô quanh van tăng sinh ( pannus overgrowth) xâm lấn gây rối loạn hoạt động van nhân tạo được ghi nhận với 27 $\mathrm{TH}$, tất cả đều ở vị trí van ĐMC. 16 trường hợp được xác nhận khi mổ lại ; các trường hợp khác được chẩn đoán bằng siêu âm tim qua ngã thực quản ( ghi nhận có độ chênh áp qua van nhân tạo rất cao và có hình ảnh mô xâm lấn dưới van) và soi van dưới màn hình tăng sáng thấy có cử động bất thường của dĩa van. Nhìn chung tất cả các trường hợp có pannus đều có độ chênh áp qua van $Đ M C$ rất cao $(>70 \mathrm{mmHg}$ ) và có thời gian mổ trên 5 năm.Trong số các $\mathrm{BN}$ này có đến 21/27 TH được thay van số 19, 4 TH thay van số $19 \mathrm{~S}$ và $2 \mathrm{TH}$ thay van số 21 . Đa số các trường hợp này đều không hoặc ít có triệu chứng lâm sàng, chỉ 6/27 TH có biểu hiện suy tim mức độ NYHA II.

Hình la và 1b: Pannus xâm lấn dưới van $Đ M C$

Bảng 3: Các biến chứng muộn liên quan

\begin{tabular}{|c|c|c|c|}
\hline Biến chứng liên quan & Thay hai lá & Thay 2 lá +ĐMC & Thay van ĐMC \\
\hline Tổng tháng theo dõi & $151,9 \pm 54,5$ & $159,8 \pm 49,2$ & $147,3 \pm 53,2$ \\
\hline ( số năm theo dõi) & (9420,5 BN-năm) & (4779,6 BN-năm) & (3362,7 BN-năm) \\
\hline Tử vong muộn & $36(4,8 \%)$ & $14(3,9 \%)$ & $27(9,9 \%)$ \\
\hline Thuyên tắc & $24(3,2 \%)$ & $13(3,6 \%)$ & $13(4,7 \%)$ \\
\hline Huyết khối van & $38(5,1 \%)$ & $13(3,6 \%)$ & $4(1,5 \%)$ \\
\hline & Fibrinolysis $=26$ & Fibrinolysis $=9$ & Fibrinolysis $=3$ \\
\hline Viêm nội tâm mạc & $2(0,2 \%)$ & $3(0,9 \%)$ & $7(2,6 \%)$ \\
\hline Sút van & 1 & $3(0,9 \%)$ & 2 \\
\hline Pannus xâm lấn & 0 & $22(6,1 \%)$ & $5(1,8 \%)$ \\
\hline Chảy máu: nhẹ & $104(14 \%)$ & $57(15,9 \%)$ & $31(11,3 \%)$ \\
\hline nặng & $29(4 \%)$ & $11(3,1 \%)$ & $7(2,6 \%)$ \\
\hline Mổ lại & $26(3,5 \%)$ & $23(6,4 \%)$ & $10(3,6 \%)$ \\
\hline
\end{tabular}


Số liệu chi tiết về biến chứng của từng nhóm được trình bày trong bảng 3 .

Tần suất đường thẳng của huyết khối van, thuyên tắc, chảy máu nặng, viêm nội tâm mạc và mô xâm lấn lần lượt là $0,31 \%, 0,28 \%, 0,267 \%, 0,068 \%$ và $0,15 \% \mathrm{BN} /$ năm.

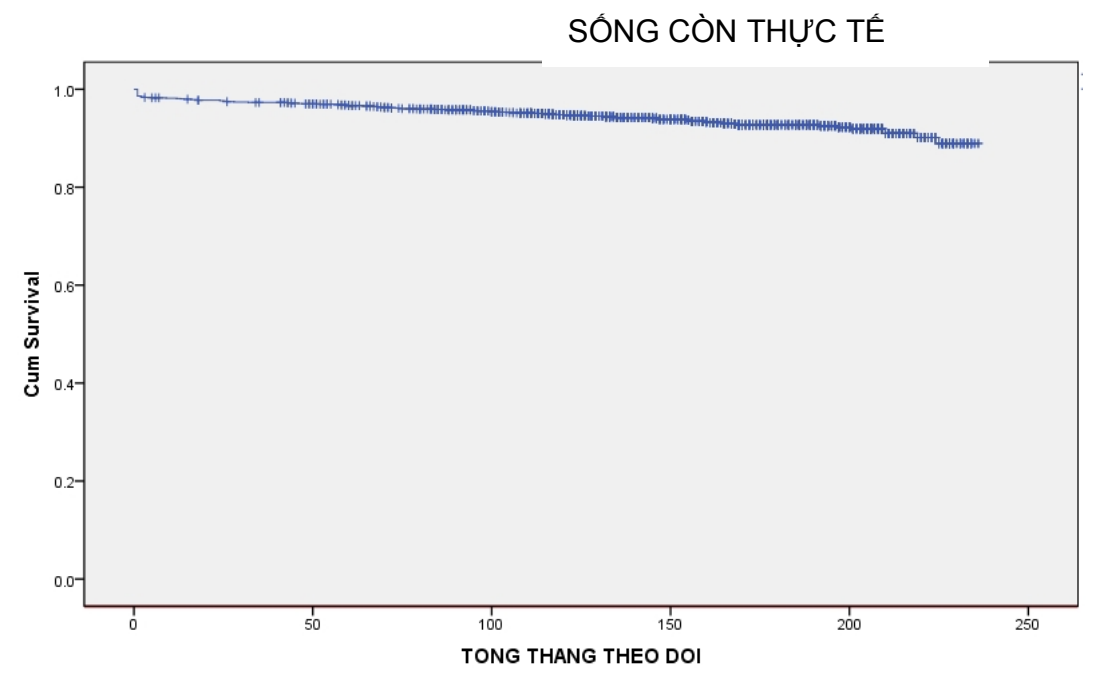

Biểu đồ 2: Sống còn thực tế KM sau 19 năm theo dõi

\section{BÀN LUẬN :}

- Van Sorin Bicarbon có phù hợp với $\mathrm{BN}$ Việt Nam ? Khi phải thay van tim bằng

van nhân tạo cơ học, ưu tiên hàng đầu là sự tương thích giữa van và tình trạng $\mathrm{BN}$. Có khoảng hơn 300000 trường hợp được thay van tim nhân tạo mỗi năm trong đó riêng ở Bắc Mỹ là hơn 100000 trường hợp. Hiện tại chưa có một loại van nhân tạo cơ học nào được xem là lý tưởng tuy nhiên đa số các tác giả đồng thuận là loại van nào có tính sinh huyết khối ( thrombogenicity ) thấp nhất và có diện tích hiệu dụng ( effective orifice area) lớn nhất sẽ là loại van được chọn ưu tiên. Có rất nhiều nghiên cứu về các loại van nhân tạo như Saint Jude Medical, Medtronic-ATS, OnX nhưng lại có khá ít nghiên cứu về van Sorin Bicarbon. Nghiên cứu phân tích gộp của Borman và Azanoush đã cho thấy về dài hạn van Bicarbon có tỉ lệ biến chứng liên quan đến van khá thấp và hoàn toàn không ghi nhận một trường hợp nào bị hư hại cấu trúc van [3], [5].Nghiên cứu của chúng tôi cũng không có trường hợp nào bị hư cấu trúc van. Về các biến chứng có liên quan đến van chúng tôi so sánh van Sorin Bicarbon với các tác giả khác đã cho thấy có sự khác biệt có ý nghĩa: tỉ lệ thuyên tắc và xuất huyết có liên quan thuốc kháng đông thấp hơn trong khi tỉ lệ huyết khối van thì cao hơn. Điều này có thể liên quan mật thiết đến việc sử dụng thuốc kháng vitamin $K$ và việc theo dõi INR định kỳ. Chúng tôi duy trì INR trong vùng trị liệu theo hướng dẫn của hiệp hội tim mạch châu Âu, từ 22,5 với van ĐMC và từ $2,5-3$ với van hai lá. Tuy nhiên, một nửa số BN bị huyết khối van đã không tuân thủ qui trình điều trị kháng đông điều này cho thấy vấn đề hướng dẫn cho $\mathrm{BN}$ mang van nhân tạo ở Việt Nam là hết sức quan trọng.

Với van SJM loại Master, Remadi cũng không ghi nhận một trường hợp nào bị hư

cấu trúc van sau 15 năm theo dõi [20]

- Cở van hai lá và van ĐMC chúng tôi thường dùng nhất $27 \mathrm{~mm}$ và $21 \mathrm{~mm}$, nhỏ

hơn nếu so sánh với các nghiên cứu nước ngoài khác. Nghiên cứu của Azanoush, Borman, Camillieri, Cotrufo, Remadi đều cho thấy cở van hai lá và $\mathrm{ĐMC}$ được thay nhiều nhất lần lượt là 29 và $23 \mathrm{~mm}$. Điều này khá hợp lý vì $\mathrm{BSA}$ của người $\mathrm{VN}$ nhỏ hơn đáng kể khi so sánh với người châu Âu, châu Mỹ. 


\section{Bảng 4 : So sánh các biến chứng liên quan đến van về dài hạn ( \%/BN-năm)}

\begin{tabular}{|c|c|c|c|c|c|c|}
\hline $\begin{array}{c}\text { Loại van } \\
\text { (tác giả -năm) }\end{array}$ & $\begin{array}{l}\text { Huyết } \\
\text { khối }\end{array}$ & $\begin{array}{c}\text { Thuyên } \\
\text { tắc }\end{array}$ & $\begin{array}{c}\text { Xuất huyết } \\
\text { nặng }\end{array}$ & VNTM & $\begin{array}{l}\text { Hư van không } \\
\text { do cấu trúc }\end{array}$ & $\begin{array}{l}\text { Mồ } \\
\text { lại }\end{array}$ \\
\hline \multicolumn{7}{|l|}{ Sorin Bicarbon } \\
\hline Azarnoush - 2010 & 0,10 & 0,81 & 1,46 & 0,22 & 0,51 & 0,4 \\
\hline Spiliopoulos - 2009 & 0,04 & 1,33 & 1,21 & 0,16 & 0,7 & 0,69 \\
\hline Borman - 2002 & 0,27 & 1,14 & 0,8 & 0,37 & 0,31 & 0,59 \\
\hline Celiento - 2014 & 0,09 & 0,34 & 0,2 & 0,05 & NA & 0,11 \\
\hline Misawa - 2015 & NA & 0,5 & 0,5 & 0,2 & NA & 0,4 \\
\hline Chúng tôi - 2018 & 0,31 & 0,28 & 0,267 & 0,068 & 0,04 & 0,33 \\
\hline \multicolumn{7}{|l|}{ CarboMedics } \\
\hline Bouchard-2014 & 0,135 & 0,59 & 0,57 & 0,22 & NA & 0,72 \\
\hline Kang- 2005 & 0,25 & 0,75 & 0,8 & 0,3 & 0,074 & 0,23 \\
\hline \multicolumn{7}{|l|}{ SJM } \\
\hline Ikonomidis - 2003 & NA & $2-3,4 \%$ & NA & 0,5 & NA & 0,7 \\
\hline Remadi - 1998 & 0,21 & 0,75 & 0,91 & 0,14 & 0,48 & 0,42 \\
\hline \multicolumn{7}{|l|}{ Medtronic ATS } \\
\hline Sezai - 2010 & 0 & 0,44 & 0,19 & 0 & 0,12 & NA \\
\hline Baykut- 2006 & 0,04 & 1,1 & 0,5 & 0,1 & 0,6 & 0,24 \\
\hline
\end{tabular}

- Hiện tượng mô xâm lấn gây rối loạn hoạt động van nhân tạo ( pannus

overgrowth) : nghiên cứu $1186 \mathrm{BN}$ thay van ĐMC bằng van Medtronic-Hall, Ellensen báo cáo có $27 \mathrm{TH}(2,3 \%)$ có pannus dưới van ĐMC hình thành trung bình sau 11,1 năm. Đáng chú ý là $7 \mathrm{TH}$ đã chết trước khi kịp can thiệp. Tương tự, Sakamoto báo cáo tỷ lệ pannus ở van một dĩa Bijork-Shiley là $2,4 \%$ và van hai nửa dĩa St Jude Medical chỉ là $0,73 \%$. Tác giả cho rằng yếu tố kích hoạt hình thành mô xâm lấn ở van một dĩa là do hiện tượng dòng máu xoáy khi đi qua lỗ nhỏ và lỗ van quá nhỏ sau khi thay van hai nửa dĩa [21]. Trong thực tế trên lâm sàng rất ít trường hợp có triệu chứng.Cần nghi ngờ có mô xâm lấn khi: (1) $\mathrm{BN}$ đã được thay van từ 5 năm trở lên; (2) siêu âm tim ghi nhận có độ chênh áp qua van cao bất thường và có hình ảnh mô tăng sinh đặc trưng; (3) soi van trên màn hình tăng sáng thấy có cử động bất thường của dĩa van (loại trừ hiện tượng kẹt dĩa van). Trong nghiên cứu này có 27 $\mathrm{TH}$ ghi nhận có mô xâm lấn gây rối loạn hoạt động van ĐMC với tỷ lệ 4,3\% cao hơn nhiều khi

so với các tác giả khác. Hiện tượng mô xâm lấn này dẫn đến bất tương xứng van nhân tạo- bệnh nhân ( patient-prosthesis mismatch-PPM ) thứ phát. Bất tương xứng van nhân tạo-bệnh nhân nguyên phát xảy ra trong các trường hợp khi diện tích hiệu dụng của van được thay quá nhỏ không tương xứng với diện tích cơ thể $\mathrm{BN}$. Cụ thể khi $\mathrm{EOA}<0,65 \mathrm{~cm} 2 / \mathrm{m} 2 \mathrm{BSA}$ tương đương $\mathrm{PPM}$ nặng và $0,65 \mathrm{~cm} 2 / \mathrm{m} 2<\mathrm{EOA}<0,85 \mathrm{~cm} 2 / \mathrm{m} 2$ tương đương PPM trung bình. Nghiên cứu phân tích gộp của Head và CS ( với $23186 \mathrm{BN}$ ) đã cho thấy về dài hạn, bất tương xứng van-BN làm tăng nguy cơ tử vong có liên quan đến van [14]. Sezai ghi nhận ( trên siêu âm ) có đến $83,3 \%$ số $\mathrm{BN}$ thay van ĐMC cở $19 \mathrm{~mm}$ bị PPM mức độ trung bình và nặng [23]. Một nghiên cứu với $3609 \mathrm{BN}$ được thay van ĐMC của Kaminishi và $\mathrm{CS}$ cho thấy tỷ lệ PPM lên đến $8,5 \%$ và tỷ lệ tử vong sớm ở nhóm PPM là 3,9\% gấp đôi so với nhóm không PPM [18]. Để tránh tình trạng này cần cân nhắc chọn các loại van dạng supra-annular với kích cở nhỏ nhất là $21 \mathrm{~mm}$ ( ở người trưởng thành). Nếu vòng van $\mathrm{ĐMC}$ của $\mathrm{BN}$ quá nhỏ cần mở rộng 
vòng van theo phương pháp Manougian hoặc Carpentier. Một số ít trường hợp mổ lại để thay van lớn hơn cần mở rộng theo phương pháp Konno-Rastan.

\section{KẾT LUẬN :}

- Nghiên cứu theo dõi dài hạn đã cho thấy van Sorin Bicarbon có hiệu năng tốt, tính tương thích cao và ít gặp biến chứng liên quan.

- Về lâu dài, nhằm giảm thiểu biến chứng mô cơ tăng sinh gây rối loạn chức năng van ĐMC và tránh hiện tượng bất tương xứng van nhân tạobệnh nhân ở vị trí van ĐMC nên chọn kích cỡ van tương đương 21 trở lên .

\section{TÀI LIỆ THAM KHẢO}

1. CW Akins, C Miller, MI Turina, NT Kouchoukos, EH Blackstone, GL Grunkemeier, JM Takkenberg, TE David, EG Butchart, DH Adams, DM Shahian, S Hagl, JE Mayer, and BW Lytle. Guidelines for reporting mortality and morbidity after cardiac valve interventions. $J$ Thorac Cardiovasc Surg 2008; 135:732-8

2. Akhtar RP, Abid AR, Zafar H, Cheema MA, Khan JS. Anticoagulation in Pregnancy with Mechanical Heart Valves: 10-Year Experience. Asian Cardiovasc Thorac Ann 2007;15:497-501.

3. Azarnoush K, Laborde F, de Riberolles CM. The Sorin Bicarbon over 15 years clinical outcomes: multicentre experience in 1704 patients. Eur J Cardiothorac Surg 2010;38: 759-766.

4. Borman JB, Brands WGB, Camilleri L, Cotrufo M, Daenen W, Gandjbakhch I, et al. Bicarbon valve - European multicenter clinical evaluation. Eur $J$ Cardiothorac Surg 1998;13:685-93.

5. Borman JB, de Riberolles CM. Sorin Bicarbone bileaflet valve: a 10-year experience. Eur J Cardio-thorac Surg 2003; 23: 86-92.

6.Baykut D, Grize L, Schindler C et al. Eleven-year single-center experience with the
ATS open pivot bileaflet heart valve. Ann Thorac Surg 2006 ;82:847-52.

7. Bouchard D, Mazine A, Stevens L-M, Pellerin M, Cartier R, Demers P, et al. TwentyYear Experience With the CarboMedics Mechanical Valve Prosthesis . Ann Thorac Surg 2014;97:816-23

8. de Carlo M, Milano AD, Nardi C, Mecozzi G, Bortolotti U. Serial Doppler echocardiographic evaluation of small-sized Sorin Bicarbon prostheses. $J$ Thorac Cardiovasc Surg 2003;126:337-343.

8. Camilleri LF, Bailly P, Legault BJ, Miguel B, D'Agrosa-Boiteux MC, de Riberolles $\mathrm{CM}$. Mitral and mitro-aortic valve replacement with Sorin Bicarbon valves compared with St. Jude Medical valves.CardioVasc Surg 2001;9 (3):272-280.

9. Celiento M, Filaferro L, Milano AD, Anastasio G, Ferrari G, Bortolotti U . Single center experience with the Sorin Bicarbon prosthesis: A 17-year clinical follow -up. $J$ Thorac Cardiovasc Surg 2014;148:2039-44.

10. Cotrufo M, Festa M, Renzulli A, de Luca L, Sante P, and Giannolo B. Clinical results after cardiac valve replacement with the Sorin prosthesis: A 6-year experience. Eur J Cardiothorac Surg 1988: 2: 355-359.

10. Emery $\mathrm{RW}$, Krogh $\mathrm{CC}$, Arom $\mathrm{KV}$, Emery AM, Benyo-Albrecht K, Joyce LD, et al. The St. Jude Medical cardiac valve prosthesis: a 25-year experience with single valve replacement. Ann Thorac Surg 2005;79:776-83.

11. Ellensen VS, Andersen KS, Vitale N, Davidsen ES, Segadal L, and Haaverstad R Acute Obstruction by Pannus in Patients With Aortic Medtronic-Hall Valves: 30 years of Experience. Ann Thorac Surg 2013;96:2123-8.

12. Garatti $\mathrm{A}$, Mori $\mathrm{F}$, Innocente $\mathrm{F}$, Canziani A, Gagliardotto P, Mossuto E, et al. Comparative Evaluation of Small-Size Sorin 
Slimline and St. Jude HP Heart Valve Prostheses Aortic Valve Replacement With 17-mm Mechanical Prostheses: Is Patient-Prosthesis Mismatch a Relevant Phenomenon? . Ann Thorac Surg 2005; 79:1284-90.

13. Goldsmith I, Lip GYH, Patel RL. Evaluation of the Sorin bicarbon bileaflet valve in 488 patients (519 prostheses). Am J Cardiol 1999;83:1069-74.

14. Head SJ, Mokhles MM, Osnabrugge RLJ, Pibarot P, Mack MJ, Takkenberg JM,

et al. The impact of prosthesis-patient mismatch on long-term survival after aortic valve replacement:a systematic review and metaanalysis of 34 observational studies comprising 27186 patients with 133141 patient-years. European Heart Journal 2012; 33 :1518-1529.

15. Kang $\mathrm{CH}$, Ahn $\mathrm{H}$, Kim $\mathrm{KH}$, Kim KB. Long-term result of 1144 CarboMedics mechanical valve implantations. Ann Thorac Surg 2005; 79: 1939-44.

16. Ikonomidis JS, Kratz JM, Crumbley III AJ, Stroud MR, Bradley SM, Sade RM, et al. Twenty-year experience with the St. Jude Medical mechanical valve prosthesis. J Thorac Cardiovasc Surg 2003;126:2022-31.

17. Josa M, Castell M, Par C, Bedini JL, Cartad R, Mestres CA, et al. Hemolysis in Mechanical Bileaflet Prostheses: Experience With the Bicarbon Valve. Ann Thorac Surg 2006;81:1291- 1296.

18. Kaminishi Y, Misawa Y, Kobayashi J,Konishi H, Miyata H, Motomura N. Patientprosthesis mismatch in patients with aortic valve replacement. Gen Thorac Cardiovasc Surg (2013) 61:274-279 .

19. Misawa $\mathrm{Y}$, Muraoka A, Ohki S, Aizawa K, Kawahito K, Saito T, et al. Fifteenyear experience with the Bicarbon heart valve prosthesis in a single center. J Cardiothorac Surg 2015;10:89

20. Remadi JP, Bizouarn P, Baron O, Al Habash O, Despins P, Michaud JL, et al. Mitral Valve Replacement With the St. Jude Medical Prosthesis: A 15-Year Follow-up. Ann Thorac Surg 1998;66:762-7.

21. Reyes G, Badia S, Alvarez P, Kallmeyer C, Rodriguez S, Sarraj A et al. Results of aortic valve replacement with the supra-annular Sorin Bicarbon Overline prosthesis. $J$ Heart Valve Dis 2012 ; 21(3):358-363.

22. Sakamoto $Y$, Hashimoto $K$, Okuyama $\mathrm{H}$, Ishii S, Shingo T, Kagawa H. Prevalence of pannus formation after aortic valve replacement: clinical aspects and surgical management. J Artificial Organs 2006;9(I3) : 199-202.

23. Spiliopoulos K, Haschemi A, Parasiris $\mathrm{P}$, Kemkes BM. Sorin Bicarbon ${ }^{\mathrm{TM}}$ bileaflet valve: a 9.8-year experience. Clinical performance of the prosthesis after heart valve replacement in 587 patients. Interact CardioVasc Thorac Surg 2009; 8: 252-259.

24. Sezai A, Hata M, Niino T, Yoshitake I, Kasamaki Y, Hirayama A, Minami K. Fifteen years of experience with ATS mechanical heart valve prostheses. J Thorac Cardiovasc Surg 2010; 139: 1494-500. 